Distribution Category:

Magnetic Fusion Energy (UC-420)

ANL/FPP/TM--223

DE88 013326

ANL/FPP/TM-223

ARGONNE NATIONAL LABORATORY

9700 South Cass Avenue

Argonne, I11 inois 60439-4801

EDDY CURRENT ANALYSIS IN FUSION DEVICES

\title{
(⿸丆口
}

L.R. Turner

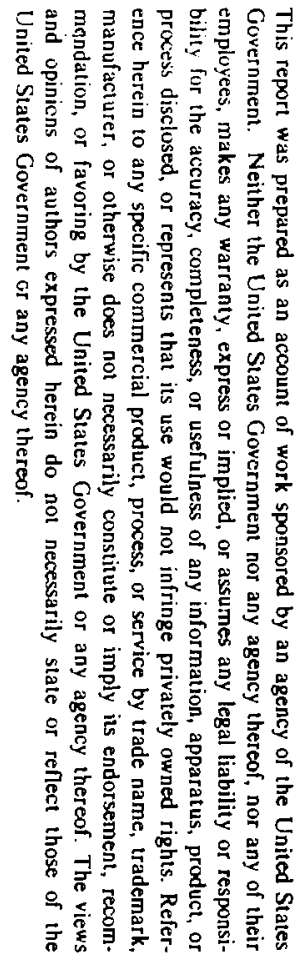

Work supported by

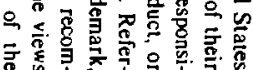

June 1988

Office of Fusion Energy

U.S. Department of Energy

Under Contract W-31-109-Eng-38 
TABLE OF CONTENTS

Page

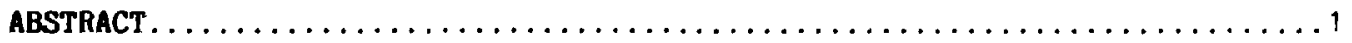

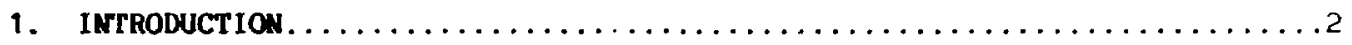

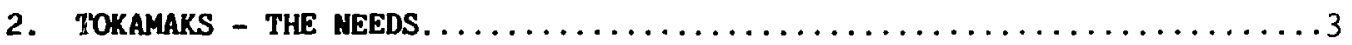

3. TOKakaks - modelling THE INTERaction of Plasma and fWBS...........5

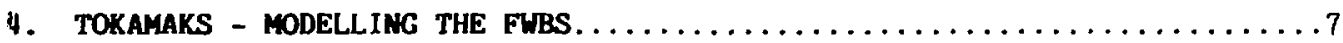

5. TOKAMAKS - COUPLING EDDY CURRENTS AND MOTION. $\ldots \ldots \ldots \ldots \ldots \ldots \ldots \ldots$

6. REVERSED FIELD PINCH. $\ldots \ldots \ldots \ldots \ldots \ldots \ldots \ldots \ldots \ldots \ldots \ldots \ldots \ldots \ldots \ldots$

7. Conclusions. $\ldots \ldots \ldots \ldots \ldots \ldots \ldots \ldots \ldots \ldots \ldots \ldots \ldots \ldots \ldots \ldots \ldots$

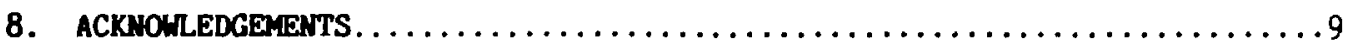

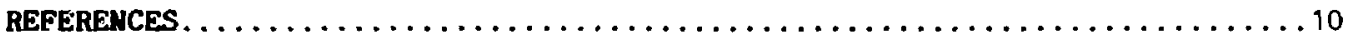




\section{EDDY CURRENT ANALYSIS IN FUSION DEVICES}

by

L.R. Turner

\section{ABSTRACT}

In magnetic fusion devices, particularly tokamaks and reversed field pinch (RFP) experiments, time-varying magnetic fields are in intimate contact with electrically conducting components of the device. Induced currents, fields, forces, and torques result. This note reviews the analysis of eddy current effects in the following systems.

1. Interaction of a tokamak plasma with the eddy currents in the first wall, blanket, and shield (FWBS) systems.

2. Eddy currents in a complex but two-dimensional vacuum vessel, as in TFTR, $\mathrm{JET}$, and JT-60.

3. Eddy currents in the FWBS system of a tokamak reactor, such as NET, FER, or ITER.

4. Eddy currents in a RFP shell.

The cited studies are chosen to be illustrative, rather than exhaustive. 


\section{INTRODUCTION}

In devices for the study and application of magnetic fusion, particularly in tokanaks, time-varying magnetic fields are in intimate contact with electrically conducting components of the device. Induced currents, fields, forces, and torques result. Analysis of these electromagnetic effects is required in order to design a device with mechanical integrity and predictable operation.

Jukes (1) identified many computer codes for engineering design in fusion, including time-varying electromagnetics. Earlier, Lari and Turner(2) attempted a comprehensive survey of eddy-current codes for all applications. The survey listed forty two-dimensional (2-D) and three-dimensional (3-D) codes. Other codes existed at the time it was published, and today there must be several times that many. Molinari ${ }^{(3)}$ is carrying out an ongoing tabulation of commercially available codes.

What is most striking in surveying the $3-D$ eddy current analysis for fusion devices, and for other applications as well, is the variety of methods and variables that have been employed. Most 2-D analyses use the finite element method (FEM) with the one-component vector potential A as variable. In 3-D analysis, particularly for complex geometries such as a tokamak firstwall, blanket and shield (FWBS) system, there is no one standard method or choice of variables.

This note can only sketch an outline of the approaches that have been tried in eddy current analysis of tokamaks and other experiments. Fortunately, two ongoing series of conferences and seminars provide descriptions of individual codes and methods: the biennial COMPUMAG conferences (Oxford 1976, Grenoble 1978, Chicago 1981, Genoa 1983, Colorado 1985, Graz 1987, and Tokyo 1989), and the biennial eddy current seminars at the Rutherford Appleton Laboratory (RAL) in 1981, 1982, 1984, 1986, and 1988. Beginning with Chicago, the COMPUMAG proceedings have been published in IEEE Transactions on Magnetics ${ }^{(4)}$. Proceedings of the earlier COMPUMAC Conferences and of the RAL seminars were published by the hosts; some of these may still be available. 


\section{TOKAMAKS - THE NEEDS}

The First Wall, Blanket and Shield (FWBS) system of a tokamak reactor can experience several electromagnetic effects. Four of these are:

1. Plasma stabilization and reduction of plasma motion.

2. Protection of the reactor systems against the electromagnetic consequences of a plasma disruption.

3. Delay of the penetration of ohmic-heating flux and control field from cuils outside the blanket into the plasma region.

4. Eddy current forces and torques on FWBS components.

In general, the first two effects aid the operation of the reactor while the last two hinder it. However, it is difficult to take advantage of the former without having to deal with the latter.

Distinction should be made between the electromagnetic effects in existing devices and in future fusion experiments and reactors. First, in existing jevices, the induced eddy currents are almost entirely toroidal while in future tokamaks, the currents will be more complex, with poloidal components and possibly radial components as well. Second, plasmas in existing tokamaks are surrounded by thin vacuum vessels, with short time constants with very little delay and perturbation of the poloidal field. Plasmas in future tokamaks will be surrounded by thick FWBS structures, which will introduce sizable poloidal field delays and perturbations.

Most existing fusion experiments, TFTR, JT-60, and JET in particular, have bellows or other segments to provide continuous but high resistance first wall current paths. The high resistance bellows sections decrease the $L / R$ time constant of the first wall, facilitate magnetic flux penetration, and tend to limit the induced current flowing in the first wall; but to rirst order they do not change or constrict the current path. Induced currents flow toroidally, do not interact with the toroidal field, and can generally be modelled by a relatively small number of coaxial current loops. Other fusion devices, such as PLT, have had a dielectric break in the vacuum vessel to prevent circulating currents. Opposite currents flow on the inside and outside surfaces of the vessel, and the currents decay even more quickly, but their analysis is similarly fairly straightforward. 
By contrast, future tusion reactors will have segmented FWBS components to permit remote maintenance and convenient replacement of FWBS sectors. Induced currents in the first wall will flow from sector to sector at a limited number of electrical connectors. Current paths will not be strictly toroidal; there will be poloidal current components where the current constructs near the connectors. If maintenance and materials considerations force the connectors to be located at the back of the FWBS sectors rather than at the first wall, there will be radial currents as well. (Concerns about arcing may eliminate this design alternative.) These radial and poioidal currents and the non-axisymmetric toroidal currents will introduce transient field ripple into the plasma region, possibly up to many hundreds of gauss in magnitude. Whereas toroidal currents interact only with the poloidal field, the radial and poloidal currents will interact with the toroidal field, typicaliy ten times stronger, and produce a severe and complex distribution of forces and torques.

The segmentation of the FWBS system to facilitate remote maintenance also introduces the possibility of electrical arcing between segments during a plasma disruption. If arcing welds neighboring FWBS or limiter sectors together, removal and replacement of the sectors may result in months of delay. The danger of arcing may well require that the electrical connectors between sectors lie no more than $10 \mathrm{~cm}$ from the first wall despite the increased thermal, radiation, and maintenance difficulties that result. Even if arcing does not weld neighboring sectors together, it can provide a lowresistance current path between them and produce eddy currents, forces, and torques far higher than those designed for the nominal case of no arcing.

The field from the EF (Equilibrium Field) coils and flux from the OH (Ohmic Heating) coils must penetrate into the plasma regic, without undue delay or distortion. In existing fusion experiments, the major encumbrance to field penetration is the thin and high-resistance first wall, deliberately designed to have a short $L / R$ time constant $(0.5 \mathrm{~ms}$ in JET, $3 \mathrm{~ms}$ for TFTR) in order to minimize electromagnetic delay.

However, in future fusion reactors, the major encumbrance to field penetration will be the thick blanket and shield sectors, truly threedimensional bodies, with large thickness relative to the skin depth and $L / R$ time constants of order 100 to $300 \mathrm{~ms}$. Moreover, the gaps between sectors 
will be small and convoluted to prevent neutron streaming. The computation of a complete 3-D system with narrow gaps is beyond existing capability.

Finally, non-axisymmetric conducting first wall segments, electrical connectors between those segments, and active or passive saddle coils enclosing the plasma region may be needed for the control of plasma position. However, these conducting elements may interact electromagnetically with the changing magnetic fields from the PF coils or from a plasma disruption to create problems of force restraint or power demand which would be highly expensive or even impossible to solve through conservative design. At present, we cannot adequately determine either if such conducting elements are nceded or what complications they may introduce.

\section{TOKaMAKS - MODELLING THE INTERACTION OF PLASMa AND FWBS}

Computations of the interactions of a tokamak plasma with the FWBS system, in particular the study of plasma disruptions and their consequences, frequently display an anomaly. In some cases, the plasma is described by a detailed MHD calculation, and the surroundings treated as a perfectly conducting, axisymmetric shell. In others, the FWBS is treated as a complex 3-D geometry with varying conductivities, and the plasma as a fixed filament with current varying in a simple way, linearly or exponentially, with time.

Recently, there have been some attempts to treat the plasma and FWBS in similar detail. The DSTAR code(5) treats the plasma with the Tokamak Simulation Code (TSC) $(6)$, and models the FWBS with many resistive loops inductively coupled to each other and to the plasma. TSC solves the coupled MHD and Maxwell's equations for a resistive plasma. DSTAR has been applied to the Tokamak Fusion Core Experiment (TFCX) $^{(5)}$ and to TIBER-II.

Segmentation of the FWBS is modelled in DSTAR by requiring a zero net circulating current in the loops representing the FWBS. That is a reasonable first approximation for segmentation effects, but is unsatisfactory in certain regards.

First the paths and the magnitudes of the poloidal and radial (P\&R) currents are not determined, and so it is not possible to calculate the forces arising from the interaction of the $P \& R$ currents with the toroidal field. 
Second, for a highly segmented FWBS (16 or more segments), the P\&R portions of the current paths may have resistance as high as that of the toroidal portions, or even higher. The P\&R resistance will affect the magnitude and distribution of the toroidal currents. Inductive effects from the P\&R currents may have similar effects.

The NET (Next Europear, Torus) Team have undertaken a fuller treatment of electromagnetic effects on the FWBS from plasma descriptions using the two

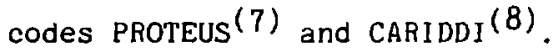

PROTEUS is an axisymmetric finite element code to study plasma behavior. It is used to model plasma evolution, instabilities, and disruptions. It can include external structure (passive stabilization) and circuits (e.g. active stabilization). The code can treat non-linear iron; hence it can be calibrated to JET results.

Diffusion effects are calculated simultaneously with MHD equilibrium through a Galerkin procedure rather than by switching back and forth. That process improves the solution time by two or three orders of magnitude. Computations are 1 imited to a resistive time scale (i.e. the Alfen velocity is effectively infinite), neglecting inertial effects.

CARIDDI is a true 3-D integral code for the current density $J$ (actually for a unique current vector potential $T$ ). The plasma current is treated as a single filament.

There is little direct 3-D effect on the plasma from the 48 segment first wall of NET. Poloidal current on opposite sides of each gap are equal and opposite, and so there is little perturbing field. Major effects are axisymetric, namely:

1. Added resistance due to the poloidal current path,

2. Added inductance due to the field in the gap,

3. No net circulating current in the first wall.

As mentioned above, the axisymetric plasma code PROTEUS permits coupling to external circuits. Shorting elements together poloidally yields no net current, and other circuits can incorporate the resistance and inductances. 
For $\mathrm{N}$ rirst wall elements on PROTEUS, those resistances and inductances, in turn, can be determined from $\mathrm{N}-1$ runs of CARIDDI, since for solution that code calculates inductance and resistance matrices. When 1 last spoke with the NET Team ${ }^{(9)}$, they had not yet determined just what $\mathrm{N}-1$ runs should be done (ideally, orthogonal current vectors), but the method sounds like the best available with today's techniques and computers.

Presumably, the coupled computation will give P\&R currents from which Lorentz forces of the toroidal field can be determined.

\section{TOKAMAKS - MODELLING THE FUBS}

1 would date the modeling of a realistic geometry from Kameari and Suzuki's 1977 eddy current analysis(10) of the vacuum vessel and support plates of JT-60. The analysis treated the vacuum vessel as a thin shell with the two components of current density expressed as the curl of a current potential $V$. The equations were formulated from the energ: and solved by an eigenvalue approach. The code EDDYTORUS treated a segment of the odd-shaped vacuum vessel including holes and resistive regions representing the bellows. Others $(11,12)$ also treated eddy current effects at about that time.

Weissenburger (13) applied the SPARK code $(14,15)$ to the eddy current analysis of the TFTR vacuum vessel. SPARK is a network code with loop currents as variables and is now widely used for fusion applications. The TFTR vacuum vessel was modelled as a shell with high-resistance bellows sections and with many many ports and lumpy port structures. Results were presented as a movie.

More recently Chaussecourte, Bossavit, and Verite ${ }^{(16)}$ have modelled the NET first wall segment with the code TRIFOU $(17)$ and made a movie of ine eddy current distribution. In TRIFOU, the field $H$ serves as variable.

Blum et al. (18) analyzed the eddy currents in the tokamak TORE SUPRA, and Rubinacei (19) the eddy currents for INTOR and for the Ignitor experiment. Thome, Pillsbury, and Langton $(20)$ compared analytical estimates of the eddy current forces in an axisymmetric torus with the results of calculations with NMLMAP(21). Crutzen and Rubinacci(22) looked at the NFT eddy current forces with the code SCILLA. 
Kameari(23) applied the code EDDYCUFF to the complex blanket of the Fusion Experimental Reactor (FER). The mesh consisted of multiple shells and plates in several orientations.

Bell et al. (24) compared the measured field penetration through the structure of TFTR with that predicted by several models. A model by Preis (25) that included saddle currerts with resistances and inductances independert of those of the axisymmetric currents gave satisfactory agreement with the measurement.

The problem of applying the forces from an eddy current analysis to a stress analysis of the structure has been widely discussed $(23,26,27)$, but I will say nothing atout it.

\section{TOKAMAKS - COUPLING EDDY CURRENTS AND MOTION}

Bialek et al. (28) predicted a coupling between eddy currents and conductor motion, and judged that the coupling would decrease the expected deflections and stresses in the TFTR bumper limiters dramatically. If the conductor (limiter) is originally parallel to the constant (toroidal) field, and if due to the changing (plasma current) field, forces rotate the conductor so that it cuts the flux of the constant field, then that changing flux will induce currents and forces that diminish the original currents and forces, sometimes by an order of magnitude or more.

When applied to a rigid plate free to rotate, the coupling was verified first by computation with the code EDDYNET $(29,30)$ and then by analysis and experiments in the FELIX facility $(31,32)$.

When applied to a cantilevered beam, the coupling was verified by analysis and experiments on the FELIX facility $(33,34)$ and by computation( 32$)$.

\section{REVERSED FIELD PINCH}

A reversed field pinch (RFP) device has a thick stabilizing shell of high conductivity. In order that the applied fields can readily perietrate the shell, it normally has poloidal and toroidal gaps. These gaps perturb the eddy current paths and result in a net field that is not axisymmetric. Various approaches have been studied to minimize the asymmetry, e.g. compensated gaps and multiple shells with the gaps not aligned. 
Many approaches have been taken to compute the eddy current effects. Vogel and Preis (35) used a network code FEDIFF to study butt joints for the device 2T-40M. Turner $(36)$ used the code EDDYNET to compare various gaps for 2T-P. The network codes use rilament conductors and can give satisfactory results away from the walls of the shell but not near the walls. Fukuda et al. (37) compared the network code FEDIFF and an integral code using the current vector potential $\mathrm{V}$. For the $2 \mathrm{~T}-40 \mathrm{M}$, they found that the two methods gave distincily different results. The reasons for the differences are not determined. Vogel (38) modified the code FEDIFF to calculate fields from plates rather than filaments. The exaggerated waviness (sometimes an order of magnitude) of the filament effects disappeared. More analysis, as well as benchmarking of the codes, is needed.

Gnesotto et al. (39) studied the effect of gaps and holes in the RFP device RFX using the surface current density as variable. Uesaka et al. (40) did a similar study of REPUTE- 1 with the mesh code INCANET.

\section{CONCLUSIONS}

It is striking how many different approaches have been used for eddy current analyses of fusion devices. The shell seems to be particularly popular, due to its flexibility and simplicity. But even with a shell mesh, many different choices of variable and solution method are used.

The recent International Electromagnetic Workshops $(41,42)$ showed similar results when different codes were applied to the same problem. In some cases, the computing time could be cut to a fraction without changing the values of the computed quantities of interest just by recognizing the suitability of reduced dimensionality or other simplification.

\section{ACKNOWLEDGEMENTS}

The author appreciates the assistance of $H$. Fukumoto, A. Kameari, and $K$. Miya in Japan; S. Jardin, B. Merrill, and D. Weissenburger in the US; and $R$. Albanese, R. Bond, E. Coccorese, O. DeBarbieri, R. Hancox, and G. Rubinacci in Europe.

This note is based on a lecture given by the author at the First Seminar on Computational Electromagnetics, Kawaguchi-ko, Japan, 21-22 Apri1 1988. 


\section{REFERENCES}

1. J.D. Jukes, "Computer Codes for the Engineering Design of Fusion Experiments," Culham Laboratory, CLM-R-266 (1986).

2. R.J. Lari and L.R. Turner, "Survey of Eddy Current Programs," IEEE Transactions Magnetics, MAG-19, pp. 2474-2477 (1983).

3. G. Molinari, "Analysis of Performances of Existing Electromagnetic Codes," First Seminar on Computational Electromagnetics, Kawaguchi-ko, Japan, 21 22 April 1988.

4. IEEE Transactions Magnetics: MAG-18, $\$ 2$ (1982); MAG-19, \#6 (1983); MAG$21, \ldots$ (1985); MAG-24, 1 (1988).

5. B.J. Merrill and S.C. Jardin, "DSTAR: A Comprehensive Tokamak Resistive Disruption Model for Vacuum Vessel Components," Fusion Engineering and Design, Vol. 5, pp. 235-249 (1987).

6. S.C. Jardin, N. Pomphrey, and J. DeLucia, "Dynamic Modeling of Transport and Positional Control of Tokamaks," Princeton Plasma Physics Laboratory, PPPL-2258 (1985).

7. R. Albanese, J. Blum, and 0 . DeBarbieri, "Numerical Studies of the Next European Torus via the PROTEUS Code," Twelfth Conference on the Numerical Simulation of Plasmas, San Francisco (Sept. 1987).

8. R. Albanese and G. Rubinacci, "Solution of Three Dimensional Eddy Current Problems by Integral and Differential Methods," IEEE Transactions Magnetics, MAG-24, pp. 98-101 (1977).

9. R. Albanese, E. Coccorese, and D. DeBarbieri, personal communication.

10. A. Kameari and Y. Suzuki, "Eddy Current Analysis by the Finite Element Circuit Method," Proceedings 7th Symposium on Engineering Problems of Fusion Research, pp. 1386-1392 (Knoxville, 1977).

11. K. Miya, T. Takagi and Y. Tabata, "Three Dimensional Analysis of Magnetic Field and Magnet Stress Induced into Vessel by Plasma Motion," Proceedings 7th Symposium on Engineering Problems of Fusion Research, pp. 1371-1375 (Knoxville, 1977).

12. T. Takahashi, G. Takahashi, $Y$, Kazawa, and $Y$. Suzuki, "Numerical und Experimental Analysis of Eddy Currents Induced in Tokamak Machines, Proceedings 7 th Symposium on Engineering Problems of Fusion Research, pp. 1393-1397 (Knoxville, 1977).

13. D.W. Weissenburger and H.M. Fan, "Dynamic Analysiz of Eddy Currents and Forces in the TFTR Vacuum Vessel due to Plasma Disruptions," IEEE Transactions Magnetics, MAG-21, pp. 2347-2350 (1985).

14. D.W. Weissenburger and U.R. Christensen, "A Network Mesh Method to Calculate Eddy Currents on Conducting Surfaces," IEEE Transactions Magnetics, MAG-18, pp. $422-425$ (1982). 
15. D.H. Weissentiurger, "SPARK Version 1.1 User Manual," Princeton Plasma Physics Laturatory, PPPL-2494 (1988).

16. P. Chaussecourte, A. Bossavit, and J.C. Verite, "3D Eddy Current Distribution in a Tokamak First Wall During a Plasma Disruption Using TRIFOU," International Symposium on Fusion Nuclear Technology (Tokyo, April 1988).

17. A. Bossavit and J.C. Verite, "The TRIFOU Code: Solving the 3-D EddyCurrents Problems by Using $H$ as State Variable," IEEE Transactions Magnetics, MAG-19, pp. 2465-2470 (1983).

18. J. Blum, L. Dupas, C. Leloup, and B. Thooris, "Eddy Current Calculations for the Tore Supra Tokamak," IEEE Transactions Magnetics, MAG-19, pp. 2461-2464 (1983).

19. G. Rubinacci, "Numerical Computation of the Eddy Currents on the Vacuum Vessel of a Tokamak," IEEE Transactions Magnetics, MAG-19, pp. 2478-2481 (1983).

20. R.J. Thome, R.D. Pillsbury, Jr., and W.G. Langton, "Eddy Currerit Load Estimation for Toroidal Shells as a Result of Plasma Disruptions," Proceedings 9th Symposium on Engineering Problems of Plasma Research, pp. 111-114 (Chicago, 1981).

21. R.D. Pillsbury, Jr., "NMLMAP - A Two-Dimensional Finite Element Program for the Transient or Static, Linear or Non-linear Magnetic Field Problems," IEEE Transactions Magnetics, MAG-18, pp. 406-410 (1982).

22. Y.R. Crutzen and G. Rubinacci, "Evaluation of the Electromagnetic Effects on a Tokamak First Wall Caused by a Plasma Disruption Using a Thin Shell Formulation," to be published in Fusion Engineering and Design.

23. A. Kameari and S. Niikura, "EDDYTRAN Program System for Eddy Current, Electromagnetic Force and Structural Analysis," Proceedings 10th Symposium on Fusion Engineering, pp. 46-50 (Philadelphia, 1983).

24. D.I. Brown, M.G. Bell, and J. Coonrod, "Eddy Current Modelling and Poloidal Field Penetration in TFTR," Proceedings 10th Symposium on Fusion Engineering, pp. 1233-1237 (Philadelphia, 1983).

25. H. Preis," Numerical Study of the Magnetic Field Diffusion in the Toroidal Field Coils of the TFTR," Princeton Plasma Physics Laboratory, PPPL-1967 (1983).

26. D.W. Weissenburger and J.M. Bialek, "An Interface Between Eddy Current Calculation and Structural Analysis," IEE Transactions Magnetics, MAG-19, pp. 2619-2622 (1983).

27. T.E. Morizio and E.S. Bobrov, "Transient Non-Linear Solutions of Coupled Electromagnetic and Thermal Problems in Bitter Plate Magnets," IEEE Transactions Magnetics, MAG-19, pp. 2573-2576 (1983). 
28. J. Bialek, D. Weissenburger, M. Ulrickson, and J. Cecchi, "Modelling the Coupling of Magnetodynamics and Elastomechanics in Structural Analysis," Proceedings 10th Symposium on Fusion Engineering, pp. 51-55 (Philadelphia, 1983).

29. L.R. Turner and J.W. Cuthbertson, "Coupling Between Angular Deflection and Eddy Currents in the FELIX Plate Experiment," Argonne National Laboratory, ANL/FPP/TM-176 (1983).

30. L.R. Turner, "Electromagnetic Analysis for Fusion Reactors: Status and Needs," Proceedings 10th Symposium on Fusion Engineering, pp. 176-180 (Philadelphia, 1983).

31. D.H. Heissenturger, J.M. Bialek, G.J. Cargulia, M. Ulrickson, M.J. Knott, L.R. Turner, and R.B. Wehrle, "Experimental Observations on the Coupling Between Induced Currents and Mechanical Motion in Torsionally Supported Square Loops and Plates," Fusion Technology, Vol. 10, pp. 448-461 (1986).

32. D.W. Weissenburger, "Some Recent Studies of the Magnetomechanics of Magnetic Fusion Feactor Conponents," Electromagnetomechanical Interactions in Deformable Solids and Structures, Y. Yamamoto and K. Miya, editors, pp. 191-196 (North-Holland, Amsterdam, 1987).

33. T.Q. Hua, M.J. Knott, L.R. Turner, and R.B. Wehrle, "Experimental Modeling of Eddy Currents and Deflections for Tokamak Limiters," Fusion Technology, Vol. 10, pp. 1047-1052 (1986).

34. L.R. Turner and T. Hua, "Experimental Study of Coupling Between Displacements and Eddy Currents in Cantilevered Beams as Models of Tokamak Limiters," Electrnmagnetomechanical Interactions in Deformable Solids and Structures, $Y$. Yamanoto and K. Miya, editors, pp. 81-86 (North-Holland, Amsterdam, 1987).

35. H.F. Vogel and $H$. Preis, "Study on Diffusion of the Vertical Magnetic Field in the Toroidal Stabilizing Shell and Plasma of the 2T-40M Reversed Field Pinch Device," IEEE Transactions Magnetics, MAG-19, pp. 2482-2485 (1983).

36. L.R. Turner, "Eddy Current Analysis of the ZT-P Shells with EDDYNET," Computational Electromagnetics, 2.J. Cendes, editor, pp. 181-189 (NorthHolland, Amsterdam, 1986).

37. Y. Fukuda, T. Fujita, 2. Yoshida, N. Inoue, H. Hashizume, K. Miya, D.A. Baker, and H.F. Vogel, "Comparison of Error Field Calculation in a RFP Device," Proceedings International Workshop for Eddy Current Code Comparison," pp. 317-326 (Tokyo, 1986).

38. H.F. Vogel, "Magnetic Field Diffusing through a Toroidal Shell with Gap and Holes, from an Externally Applied Pulsed Magnetic Field," Los Alamos Technical Associates LS06000 (01) (1987).

39. F. Gnesotto, G. Miano, and G. Rubinacci, "Numerical Analysis of Time Dependent Field Perturbations due to Gaps and Holes in the Shell of a Reverse Field Pinch Device," IEEE Transactions Magnetics, MAG-21, pp. 2400-2403 (1985). 
40. M. Uesaka, Y. Hoshi, K. Saito, 2. Yoshida, and N. Inoue, "Eddy Current Analysis of INCANET for a Reversed Field Pinch Device," International Symposium on Fusion Nuclear Technology (Tokyo, April 1988).

41. L.R. Turner, K. Davey, C.R.I. Emson, K. Miya, T. Nakata, and A. Nicolas, "Problems and Workshops for Eddy Current Code Comparison," IEEE Transactions Magnetics, MAG-24, pp. 431-434 (1988).

42. COMPEL, Vol. 7, 1, Proceedings 1ssue (March 1988). 


\section{Internal:}

$\begin{array}{llll}\text { H. Attaya } & \text { S. Kim } & \text { L. Turner } & \text { ANL Patent Dept. } \\ \text { C. Baker } & \text { R. Lari } & \text { R. Weeks } & \text { TIS Files (3) } \\ \text { Y. Cho } & \text { R. Mattas } & \text { FPP Files (25) } \\ \text { K. Evans } & \text { W. Praeg } & \text { ANL Contract File } & \\ \text { T. Hua } & \text { D. Smith } & \text { ANL Libraries }\end{array}$

\section{External:}

DOE-OSTI, for distribution per UC-420 (37)

M.A. Abdou, University of Calfornia, Los Angeles

R. Albanese, University of Salerno

D. Baker, Los Alamos National Laboratory

J. Ballou, McDonnell Douglas Astronautics Company

S. Berk, Office of Fusion Energy

R.A. Bond, UKAEA, Culham Laboratory

G. Casini, Commission of the European Communities

2. Cendes, Carnegie Mellon University

D. Cohn, Massachusetts Institute of Technology

E. Coccorese, University of Naples

J. Crocker, EG\&G Idaho, Inc.

Y. Crutzen, Commission of the European Communities

K. Davey, Georgia Institute of Technology

C. Emson, Rutherford Appleton Laboratory

K. FuJiwara, Okayama University

R. Hancox, Culham Laboratory

T. Honma, Hokkaido University

S. Inakatsu, Kyokuto Boeki Kaisha, Ltd.

S. Jardin, Princeton Plasma Physics Laboratory

A. Kameari, Mitsubishi Atomic Power Industries, Inc.

P. Komarek, Kernforschungszentrum - Karlsruhe

S. Y. Lee, Korea Advanced Inst. of Sciences and Technology

Docent Dr. hob. K. Majorkowska-Knap, Warsaw Technical University

F. Matsuoka, Mitsubishi Heavy Industries, Ltd.

B. Merrill, EG\&G Idaho

K. Miya, University of Tokyo

R. Moir, Lawrence Livermore National Laboratory

G. Molinari, Universita' di Genova

D. Montgomery, Massachusetts Institute of Technology

F. Moon, Cornell University

T. Morisue, Nagoya Univer=ity

T. Nakata, Okayama University

R. Pillsbury, Massachusetts Institute of Technology

F. Ribe, University of Washington

Ruan Keqiang, Institute of Atomic Energy, PRC

G. Rubinacci, University of Salerno

Y. Shingu, Kyokuto Boeki Kaisha, Ltd.

T. Takagi, University of Tokyo 
N. Takahashi, Okayama University

R. Thome, Massachusetts Institute of Technology

M. Tillack, University of California, Los Angeles

C. Trowbridge, Vector Fields Ltd.

$T$. Uchida, Nagoya University

M. Uesaka, Ishikawajima-Harima Heavy Industries

H. Vogel, Los Alamos Technical Associates

Yan Weili, Hebei Institute of Technology

Wang Jingguo, North China Institute of Electric Power Engineering

D. Weissenburger, Princeton Plasma Physics Laboratory 